\title{
Hypothalamic disease in association with dysgenesis of the corpus callosum
}

\author{
S.R. Page', S.S. Nussey', J.S. Jenkins' ${ }^{1}$, S.G. Wilson ${ }^{2}$ and D.A. Johnson ${ }^{3}$ \\ 'Department of Medicine II, St. George's Hospital Medical School, Cranmer Terrace, London SW17 ORE, \\ Departments of ${ }^{2}$ Neurology and ${ }^{3}$ Neuropsychology, Atkinson Morley Hospital, Copse Hill, London SE20 ONE, \\ UK.
}

\begin{abstract}
Summary: We describe two cases of dysgenesis of the corpus callosum demonstrated by magnetic resonance. The first patient presented with chronic hyponatraemia. Investigation demonstrated re-setting of the osmoreceptor and thirst centres. The calculated threshold for arginine vasopressin (AVP) release was reduced at 252 mosmol $/ \mathrm{kg}$ while severe thirst was perceived at a plasma osmolality of $260 \mathrm{mosmol} / \mathrm{kg}$. Insulin-induced hypoglycaemia produced an exaggerated AVP response.

The second patient presented with hypothermia. The calculated threshold of AVP release was $296 \mathrm{mosmol} / \mathrm{kg}$ with increased sensitivity of AVP response to hypertonic saline. The plasma AVP response to insulin-induced hypoglycaemia was absent. Both cases had normal anterior pituitary function and psychological assessment showed a similar prefrontal defect. Specific tests of callosal function were normal.

These cases illustrate the importance of undertaking complete neuroradiological assessment of cases of unexplained hypothalamic disease regardless of the age of presentation to avoid overlooking this rare congenital association.
\end{abstract}

\section{Introduction}

Dysgenesis of the corpus callosum is a midline developmental defect. It commonly occurs in association with other major neurological abnormalities which result in mental retardation, hydrocephalus and epilepsy in childhood. ${ }^{1}$ Isolated dysgenesis is usually symptomless and is reported as an occasional incidental finding at post-mortem. ${ }^{1}$ The association of hypothalamic disease with dysgenesis is rare. ${ }^{2-4}$

We describe two patients with dysgenesis of the corpus callosum in whom detailed assessment of anterior and posterior pituitary function has been performed.

\section{Case reports}

Case 1

A 28 year old female secretary developed hyperthyroidism and at initial presentation the plasma sodium concentration was $130 \mathrm{mmol} / \mathrm{l}$ (normal range $135-145 \mathrm{mmol} / \mathrm{l})$. Hyperthyroidism recurred two years later when therapy with carbimazole was discon-

Correspondence: S.R. Page, M.R.C.P.

Accepted: 11 October 1988 tinued and she was admitted for a sub-total thyroidectomy.

The pre-operative plasma sodium concentration was $128 \mathrm{mmol} / \mathrm{l}$. Two days post-operatively the plasma sodium concentration fell to $108 \mathrm{mmol} / \mathrm{l}$ and she became confused. At this time the plasma osmolality was $223 \mathrm{mosmol} / \mathrm{kg}$ (normal range $280-300 \mathrm{mosmol} / \mathrm{kg}$ ), the urine osmolality was $566 \mathrm{mosmol} / \mathrm{kg}$ (normal range $100-1400 \mathrm{mosmol} / \mathrm{kg}$ ) and the urine sodium concentraion was $117 \mathrm{mmol} / \mathrm{l}$. Fluid restriction of $500 \mathrm{ml} /$ day was instituted and the plasma sodium concentration rose to $126 \mathrm{mmol} / \mathrm{l}$ over 3 weeks. Post-operative hypothyroidism, with a free serum thyroxine concentration of $7.6 \mathrm{pmol} / 1$ (normal range $9-28 \mathrm{pmol} / \mathrm{l}$ ) and serum thyroid stimulating hormone of $19.1 \mathrm{mU} / 1$ (normal range $0.3-5.5 \mathrm{mU} / \mathrm{l}$, responded to thyroxine $50 \mu \mathrm{g} / \mathrm{day}$. The confusional state slowly resolved and recovery was subsequently uneventful.

There was a past history of a febrile convulsion at the age of 2 years. An electroencephalogram (EEG) at that time showed asymmetrical activity between the two cerebral hemispheres but a further EEG performed when 10 years of age for assessment of enuresis was normal. Mild systemic hypertension (blood pressure 146/95-156/108 $\mathrm{mmHg}$ ) was diagnosed 1 year 
after the onset of hyperthyroidism. Investigations including urinalysis, an intravenous pyelogram, and urine collections for vanillylmandelic acid were normal. The blood pressure was controlled with nifedipine $10 \mathrm{mg}$ three times daily.

Hyponatraemia has persisted (mean plasma sodium concentration $129 \pm 0.65 \mathrm{mmol} / \mathrm{l}$, range $123-133 \mathrm{mmol} / \mathrm{l}$, $n=9$ ) over 2 years of observation and she maintains a fluid restriction of approximately $1000 \mathrm{ml}$ daily. Menstruation is regular, her temperature is normal and she has no neurological symptoms.

\section{Case 2}

A 16 year old previously healthy girl presented with drowsiness, slurring of speech and a deterioration of her school performance. Menstruation had been irregular for 3 months. Her oral temperature was $34^{\circ} \mathrm{C}$, falling to a nadir of $31.5^{\circ} \mathrm{C}$ during her admission. Neurological and general examinations were normal. During attempted warming she experienced extreme discomfort and profuse sweating occurred despite an oral temperature of $35^{\circ} \mathrm{C}$. At the end of the warming period her temperature fell rapidly to $32.5^{\circ} \mathrm{C}$. The plasma sodium concentration was normal. The EEG showed generalized slowing consistent with hypothermia. Her mean temperature during 4 months of observation was $32.4^{\circ} \mathrm{C}$ (range $31^{\circ} \mathrm{C}-34^{\circ} \mathrm{C}$ ). Whilst hypothermic she developed an ataxic gait with cerebellar incoordination; she experienced two grand mal seizures and she remained lethargic, withdrawn and drowsy. Carbamazepine $200 \mathrm{mg}$ /day was commenced and 3 weeks later her temperature rose to $36^{\circ} \mathrm{C}$ with a marked improvement in her clinical condition.

\section{Investigations and Methods}

Anterior pituitary function tests Soluble insulin $(0.15 \mathrm{U} / \mathrm{kg})$, thyroliberin $(200 \mu \mathrm{g})$ and luteoliberin $(100 \mu \mathrm{g})$ were injected intravenously after baseline blood sampling. Further samples were taken at 30 minute intervals for 2 hours. Plasma cortisol estimations were performed at 09.00 and 24.00 hours.

Hypertonic saline test Blood samples were collected before, and every 30 minutes during a 2 hour infusion of hypertonic saline $(0.45 \mathrm{M} ; 0.1 \mathrm{ml} / \mathrm{kg} / \mathrm{min})$.

Plasma renin, aldosterone and catecholamine sampling Case 1 maintained a high sodium $(>100 \mathrm{mmol} /$ day) and potassium intake $(>70 \mathrm{mmol} /$ day $)$ for 2 weeks. Baseline samples were taken after overnight recumbency and further samples were taken at 5, 10, 15 and 30 minutes after standing. All endocrine investigations in case 2 were performed during hypothermia (temperature $32^{\circ} \mathrm{C}$ ).

Analyses Plasma osmolality was measured by freezing point depression using an Advanced Digimatic $C$ Osmometer Model 3D. Plasma glucose was measured $\overrightarrow{\vec{D}}$ using a glucose oxidase method. Plasma arginine vasopressin (AVP), ${ }^{5}$ aldosterone, ${ }^{6}$ cortisol (Amerlex kit, Amersham International plc) and anterior pituitary hormones were measured by radioimmunoassay. Plasma catecholamines were measured by high performance liquid chromatography extraction with electrochemical detection. ${ }^{7}$ Plasma renin activity (PRA) was measured by the modified method of Mernard \& Catt. $^{8}$

Neuropsychological assessment Standard clinical 3 assessments of attention, learning, memory, percep- is tion, reasoning and intelligence ${ }^{9}$ were performed. In addition each patient underwent specific tests of $\underset{-}{-}$ callosal function using different sensory modalities according to the method of Bogen. ${ }^{10}$

Statistical analysis Plasma AVP and osmolality data for the patients and 10 normal subjects were subjected to linear regression analysis. The slope of the regression line was considered abnormal if it was greater on less than the mean \pm 2 s.d. of the normal slopes.

\section{Results}

Endocrine Anterior pituitary function and diurnal variation of cortisol was normal in both cases (not shown). The mean \pm 2 s.d. for the AVP/osmolality regression slopes of the 10 normal subjects was $0.37 \pm 0.54$.

Case 1 The AVP response to $0.45 \mathrm{M}$ saline showed normal sensitivity (slope 0.56 ) but the calculated threshold for AVP release was $252 \mathrm{mosmol} / \mathrm{kg}$ (normal range $283 \pm 4 \mathrm{mosmol} / \mathrm{kg}$ ) (Figure 1) and thirst was experienced at $260 \mathrm{mosmol} / \mathrm{kg}(278-290 \mathrm{mosmol} / \mathrm{kg})$. Insulin-induced hypoglycaemia produced an exaggerated rise of plasma AVP (Figure 2). The supine and erect PRA was abnormally low $(0.3 \mathrm{pmol} / \mathrm{h} / \mathrm{ml}$ supine, normal range $1.1-2.7 \mathrm{pmol} / \mathrm{h} / \mathrm{ml} ; 0.6 \mathrm{pmol} / \mathrm{h} / \mathrm{min}$ erect, normal range $2.8-4.5 \mathrm{pmol} / \mathrm{h} / \mathrm{ml}$ ) but the supine plasma aldosterone and the response to standing were normal. Supine plasma catecholamine concentrations were normal but the peak response to standing (noradrenaline $1774.4 \mathrm{pg} / \mathrm{ml}$, normal range $<1000 \mathrm{pg} / \mathrm{ml}$; adrenaline $3629.3 \mathrm{pg} / \mathrm{ml}$, normal range $<750 \mathrm{pg} / \mathrm{ml}$ ) was significantly exaggerated. 


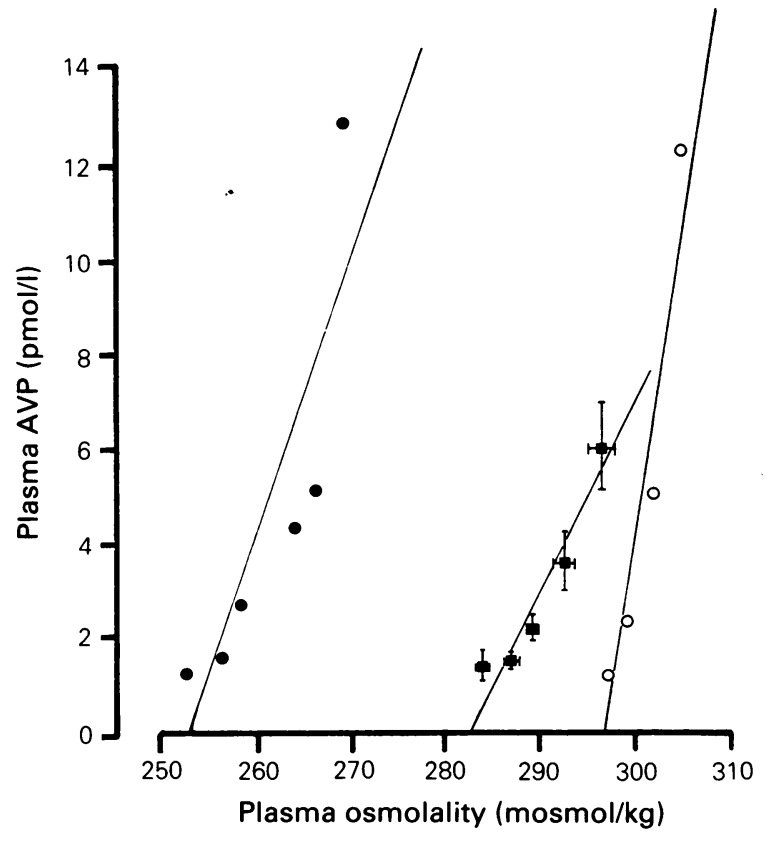

Figure 1 The relationship between plasma AVP and plasma osmolality during hypertonic saline infusion in case 1 (O) and case $2(O)$ compared with 10 normal control subjects $(\square)$. The linear regression equation for the normal subjects is $y=0.37(x-283) ; r=0.74$ $P<0.001$. The mean \pm 2 s.d. of the slopes of 10 normal subjects is $0.37 \pm 0.54$. For case 1 the equation is $y=0.56$ $(x-252) r=0.85, P<0.05$ and case 2 the equation is $\mathrm{y}=1.37(x-296) \mathrm{r}=0.95, P<0.05$.

Case 2 The plasma AVP response showed increased sensitivity (slope 1.37) and the calculated threshold of AVP release was elevated at $296 \mathrm{mosmol} / \mathrm{kg}$ (Figure 1). Insulin-induced hypoglycaemia failed to produce a rise of plasma AVP (Figure 2).

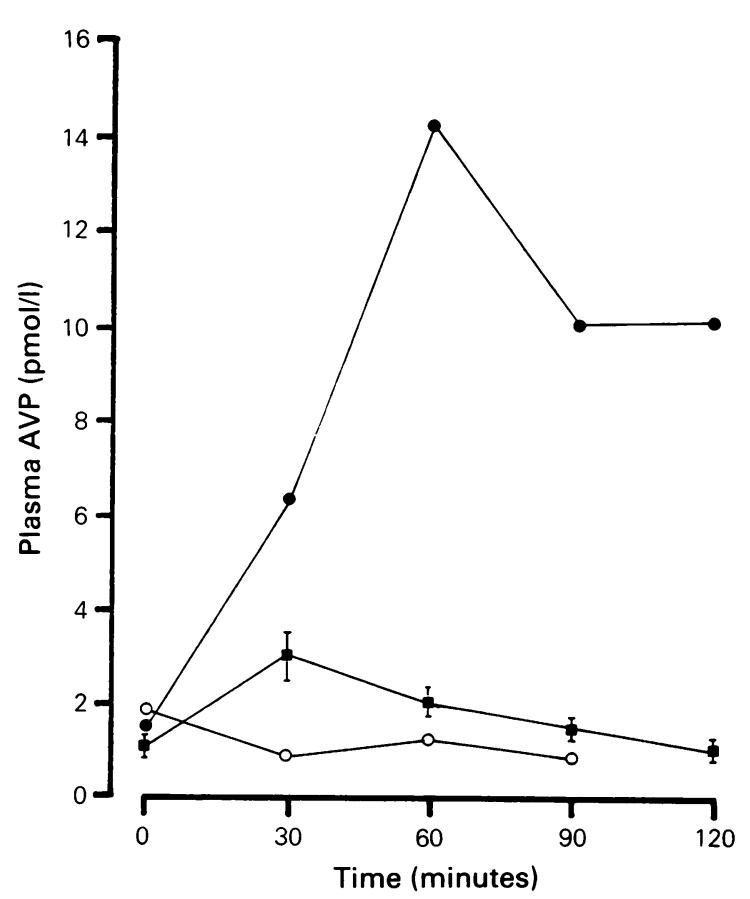

Figure 2 The AVP response to insulin-induced hypoglycaemia. Case $1=0$; case $2=0$; control subjects$=\square$ (Means \pm s.e.m. Student's $t$-test, $n=10$ ). Blood glucose nadir: case $1=1.0 \mathrm{mmol} / \mathrm{l}$, case $2=1.2 \mathrm{mmol} / \mathrm{l}$.

Radiology Magnetic resonance imaging (Siemans Magnetom 1.5T) showed dysgenesis of the corpus callosum in both cases (Figure 3). Case 2 had a high density area on both $\mathrm{T} 1$ and $\mathrm{T} 2$ weighted scans, anteriorly placed between the lateral ventricles consistent with a lipoma of the corpus callosum (Figure 3 ).
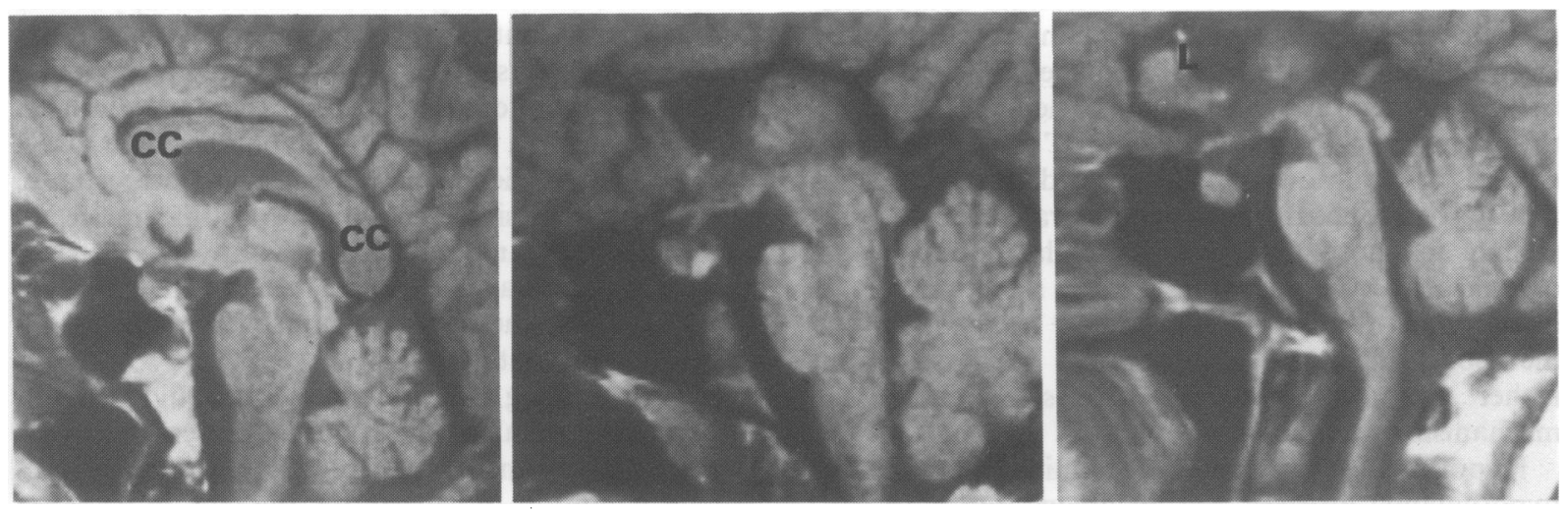

Figure 3 Cranial magnetic resonance imaging of normal corpus callosum (left), case 1 (centre) and case 2 (right). $\mathrm{CC}=$ corpus callosum, $\mathrm{L}=$ lipoma (case 2 ). 
Neuropsychological assessment Verbal IQ (case 1, 83; case 2, 93), performance IQ (case 1,75 ; case 2, 87) and full-scale IQ (case 1, 75; case 2, 90) were comparable though both patients demonstrated a marked slowing of information processing speed. Motor reaction speeds were significantly slowed in case 2 consistent with the degree of hypothermia. Immediate recall from memory, and learning ability were impaired with primary difficulties in selectivity and inhibitory control. All object naming, reading and writing were performed without error.

\section{Discussion}

The anterior hypothalamus plays a major role in osmoregulation in man by control of both the secretion of AVP from the neurohypophysis and the perception of thirst around set-points which maintain a normal plasma osmolality. ${ }^{11}$ Case 1 had resetting of the osmoreceptor threshold leading to AVP release at inappropriately low plasma osmolality but with a qualitatively normal AVP response to hypertonic saline infusion assessed by the slope of the AVP/ osmolality linear regression. The abnormal thirst set-point further maintains hypotonic plasma by encouraging drinking at low plasma osmolality and both mechanisms entirely account for the chronic symptomless hyponatraemia. The exaggerated AVP response to insulin-induced hypoglycaemia provides further confirmation of abnormalities of AVP regulation although the mechanism remains unknown. Both surgery $^{11}$ and hypothyroidism ${ }^{12}$ are potent nonosmotic stimuli to AVP secretion and would further reduce the threshold for AVP secretion. These additional factors, together with the administration of intravenous fluids post-operatively, may account for the rapid onset of severe post-operative dilutional hyponatraemia following sub-total thyroidectomy.

The exaggerated plasma catecholamine response to standing in case 1 suggests an abnormal neurogenic reflex arc which is most readily explained by additional hypothalamic disease affecting nuclei which control the sympathetic nervous system. The significance of this with regard to the mild 'essential' hypertension in case 1 is unknown. The discordant PRA and aldosterone concentrations demonstrated in case 1 are similar to those reported in unrelated conditions complicated by inappropriate AVP secretion. ${ }^{13}$ It is likely therefore that the discordancy results from the metabolic effects of inappropriate AVP secretion rather than hypothalamic disease though the mechanism is unknown.

Hypothermia is a well recognized feature of hypothalamic disease ${ }^{14}$ but an association with callosal dysgenesis is rare. Of the 10 previously reported cases all had intermittent hypothermia with episodes

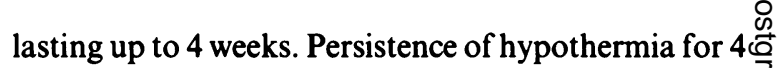
months has not been previously reported. Five cases had temperature related cerebellar ataxia. ${ }^{4}$ The pro- $\bar{z}$

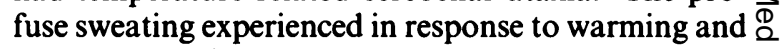
the absence of shivering in case 2 suggest abnormal $C$ control of heat conservation rather than dissipation $\overrightarrow{\vec{F}}$ though we cannot differentiate between an abnor- $\frac{\sigma}{0}$ mality in heat conservation or lowering of the thermoregulating set point. ${ }^{15}$

Both the absent AVP response to insulin-induced $\vec{\nabla}$ hypoglycaemia and the abnormalities of AVP res- $\frac{a}{0}$ ponse to hypertonic saline infusion may be due to ${ }^{\infty}$ additional hypothalamic disease. However, all inves- $\overrightarrow{0}$ tigations in case 2 were performed during hypother- $\vec{\overrightarrow{ }}$ mia. Continuation of carbamazepine therapy and the $\underset{\sigma}{\omega}$ history of seizures prevented further assessment of $\mathbb{Z}$ AVP secretion following clinical improvement and we 3 . cannot therefore exclude an effect of hypothermia on AVP secretion.

The cause of the hypothalamic disease remains $\stackrel{\text { oे }}{-}$ obscure. Water homeostasis and temperature regula- $\vec{\sigma}$ tion are unaffected in patients undergoing surgical $\omega$

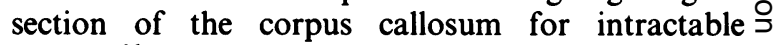
epilepsy $^{16}$ and the occasional incidental finding of $\vec{z}$ callosal dysgenesis at post-mortem ${ }^{1}$ suggests dysgenesis alone is not responsible. Midline lipomas $\frac{\partial}{\sigma}$ are a recognized association of callosal dysgenesis $s_{\circ}^{17} \vec{\imath}$ but only one of the 10 previously reported cases callosal dysgenesis with associated hypothermia hat evidence of a lipoma. ${ }^{18}$ Histological evidence of no을 specific gliosis of the anterior hypothalamus has been reported in 2 cases of intermittent hypothermia, ${ }^{4,19}$ one of which had associated callosal dysgenesis. No cause of the gliosis was found. The magnetic resonance (MR) scans of the hypothalamus in our reported cases were normal and the presence of hypothalamic gliosis remains speculative. Previous authors have suggested diencephalic epilepsy as a cause of intermittent hypothermia both with ${ }^{20}$ and without ${ }^{21}$ associated callosal dysgenesis. The apparent clinical improvement after commencing anticonvulsant therapy in case $\exists$ 2 is interesting but must be interpreted with caution. Previous reports suggest a poor overall response to anticonvulsant therapy ${ }^{4}$ and the prolonged duration $ᄋ$ of hyponatraemia in case 1 and hypothermia in case $2 \rightarrow$ argues against diencephalic epilepsy. Furthermore, periods of remission occasionally lasting for years, $\bar{N}$ independent of anticonvulsant therapy characterize the hypothermia in association with callosal dysgenesis and the apparent improvement in case $2 \mathrm{c}$ may be coincidental.

It is interesting that both patients could perform apparently normal activities before presentation despite significant impairment of many aspects of prefrontal cognition. Furthermore, the lack of evidence for classical disconnection signs ${ }^{22}$ contrasts with the severe defects resulting from surgical section of the 
corpus callosum or the presence of a callosal glioma and is consistent with previous reports. ${ }^{23}$ The timing of the developmental insult may be crucial in this respect, allowing greater functional development of noncallosal pathways, or the development of bilateral representation of important cortical function. ${ }^{24}$

In conclusion both cases illustrate the importance of undertaking complete neuroradiological assessment of cases of unexplained hypothalamic disease regard- less of the age of presentation to avoid overlooking this rare congenital association.

\section{Acknowledgements}

We thank Dr J. Britten for interpretation of the MR scans and Dr Paget Davis for referring one of the patients. S.R. Page is supported by the St George's Hospital Special Trustees and S.S. Nussey was a Wellcome Trust Lecturer.

\section{References}

1. Loeser, J.D. \& Ellsworth, C.A. Jr. Clinicopathological correlations in agenesis of the corpus callosum. Neurology 1968, 18: 745-756.

2. Fyhrquist, F., Holmberg, C., Perheentupa, J. \& Wallenius, M. Inappropriate secretion of antidiuretic hormone, hypertension and hypoplastic corpus callosum. J Clin Endocrinol Metab 1976, 45: 691-694.

3. Bannister, P., Sheridan, P. \& Penney, M.D. Chronic reset osmoreceptor response, agenesis of the corpus callosum, and hypothalamic cyst. $J$ Pediatr 1984, 104: 97-99.

4. Noel, P., Ectors, H.M., Franken, L. \& Flament-Durand, J. Agenesis of the corpus callosum associated with relapsing hypothermia. A clinicopathological study. Brain 1973, 96: 359-368.

5. Jenkins, J.S., Ang, V.T.Y., Hawthorn, J., Rosser, M.N. \& Iverson, L.L. Vasopressin, oxytocin and neurophysins in the human brain and spinal cord. Brain Res 1984, 291: $111-117$

6. Few, J.D., Chaudrey, S. \& James, V.H.T. Direct determination of aldosterone in human saliva. $J$ Steroid Biochem 1984, 21: 87-92.

7. Nussey, S.S., Prysor-Jones, R.A., Taylor, A.H., Ang, V.T.Y. \& Jenkins, J.S. Arginine vasopressin and oxytocin in the bovine adrenal gland. J Endocrinol 1987 , 115: $141-149$.

8. Mernard, J. \& Catt, K.J. Measurement of renin activity, concentration and substrate in rat plasma by radioimmunoassay of angiotensin I. Endocrinology 1972 , 90: $422-430$.

9. Lezak, M.D. Neuropsychological Assessment. Oxford University Press, Oxford, 1983.

10. Bogen, J.E. The callosal syndrome. In: Heilman, K. and Valenstein, E. (eds) Clinical Neuropsychology. Oxford University Press, Oxford, 1979.

11. Robertson, G.L., Shelton, R.L. \& Athar, S. The osmoregulation of vasopressin. Kidney Int 1976, 10: 25-37.

12. Skowsky, W.R. \& Kiruchi, T.A. The role of vasopressin in the impaired water excretion of myxoedema. $A m J$ Med 1978, 64: 613.

13. Fichman, M.P., Michelakis, A.M. \& Horton, R. Regulation of aldosterone in the syndrome of inappropriate antidiuretic hormone secretion (SIADH). J Clin Endocrinol Metab 1973, 39: 136-144.

14. Maclean, D. \& Emslie-Smith, D. Intermittent and chronic hypothermia. In: Accidental Hypothermia. Blackwell Scientific Publications, Oxford, 1977, pp. $312-333$.

15. Hockaday, T.D.R., Cranston, W.I., Cooper, K.E. \& Mottram, R.F. Temperature regulation in chronic hypothermia. Lancet 1962, ii: 428.

16. Geshwind, N. Disconnection syndromes in animals and man. Brain 1965, 88: 237-294; 585-644.

17. Patel, A.N. Lipoma of the corpus callosum: A non surgical entity. $N$ Carolina Med J 1965, 26: 328.

18. Summers, G.D., Young, A.C., Little, R.A., Stoner, H.B., Forbes, W.S.T.C. \& Jones, R.A.C. Spontaneous periodic hypothermia with lipoma of the corpus callosum. $J$ Neurosurg 1981, 44: 1094-1099.

19. Fox, R.H., Davies, T.W., Marsh, F.P. \& Urich, H. Hypothermia in a young man with an anterior hypothalamic lesion. Lancet 1970, ii: 185-186.

20. Shapiro, W.R., Williams, G.H. \& Plum, F. Spontaneous recurrent hypothermia accompanying agenesis of the corpus callosum. Brain 1969, 92: 423-436.

21. Fox, R.H., Wilkins, D.C., Bell, J.A. et al. Spontaneous periodic hypothermia: diencephalic epilepsy. $\mathrm{Br}$ Med J 1973, 2: 693-695.

22. Gott, P.S. \& Saul, R.E. Agenesis of the corpus callosum: limits of functional compensation. Neurology 1978, 28: $1272-1279$.

23. Chiarello, C. A house divided? cognitive function with callosal agenesis. Brain Lang 1980, 11: 128-158.

24. Ettlinger, G., Blakemore, C.B., Milner, A.D. \& Wilson, J. Agenesis of the corpus callosum: a behavioural investigation. Brain 1972, 95: 327-346. 